\title{
Dosage and delivery of nebulised beta agonists in hospital
}

\author{
JN STAINFORTH, RA LEWIS, AE TATTERSFIELD
}

From Southampton General Hospital, Southampton

ABSTRACT A questionnaire was sent to physicians with an interest in chest disease to determine the dose and method of delivery of nebulised beta agonists in hospital. All of the 67 physicians replying gave beta agonists by nebuliser, and all reported either salbutamol $(72 \%)$ or terbutaline $(10 \%)$ as the drug they prescribed most commonly (18\% gave either drug). There was a fivefold difference in the dose of salbutamol they prescribed most commonly (range $2 \cdot 5-12.5 \mathrm{mg}$, mode 5 $\mathrm{mg}$ ), a 20 fold difference in the volume of diluent solution used (range $0.5-10 \mathrm{ml}$, mode $2 \mathrm{ml}$ ), and a 10 fold variation in the flow rates of gas driving the nebuliser (range $1-10 \mathrm{l} / \mathrm{min}$, mode 4 $1 / \mathrm{min}$ ). There are therefore very large variations in the dose and method of delivery of beta agonists nebulised in hospital. Studies attempting to determine the optimum dose of beta agonist for use in a nebuliser need to take the type of nebuliser, diluent volume, and gas flow rate into account.

Inhalation is the preferred route for administering beta agonists because of the lower incidence of side effects for a given degree of bronchodilatation. ${ }^{12}$ The drug is usually delivered from a metered dose inhaler, though the use of nebulisers to administer beta agonists has increased recently in both hospital and domiciliary practice. The dose of beta agonist inhaled by the patient from a metered dose inhaler is about $10 \%$ of the dose administered, ${ }^{34}$ though it will be less if the inhaler is used incorrectly. ${ }^{5}$ With a nebuliser the proportion of the administered dose inhaled by the patient has varied from $1 \%$ to $12 \% .^{6-8}$ The proportion of drug inhaled from a nebuliser is likely to be more variable than that from a metered dose inhaler since it will depend on the type of nebuliser, diluent volume, and gas flow rate. We sent a questionnaire to 94 physicians to try to determine how much variation occurs in the way in which beta agonists are administered by nebuliser in hospital.

Address for reprint requests: Dr Anne Tattersfield, Level D, Centre Block, Southampton General Hospital, Southampton SO9 4XY.

Accepted 27 June 1983

\section{Method}

A single sheet questionnaire with 14 questions (appendix) was sent in January 1982 to 94 physicians with an interest in chest disease in the United Kingdom. Physicians were randomly selected from the 1981 Thoracic Society handbook. The questionnaire was designed to determine: (1) how often the physicians used a nebuliser to deliver beta agonists; (2) which beta agonist they preferred and what dose was usually given; (3) the type of nebuliser they used most often and the way in which it was used.

\section{Results}

There were 67 replies, a $71 \%$ response rate. All respondents used nebulisers to administer beta agonists in hospital. Fifty four (80\%) prescribed nebulised beta agonists more than 10 times a month.

WHICH BETA AGONIST AND WHAT DOSE?

All physicians reported either salbutamol $(5 \mathrm{mg} / \mathrm{ml})$ or terbutaline $(10 \mathrm{mg} / \mathrm{ml})$ as the beta agonist they prescribed most commonly. Salbutamol was chosen by $48(72 \%)$ respondents, terbutaline by seven $(10 \%)$, and both drugs by $12(18 \%)$. The dose of salbutamol most commonly prescribed ranged from 2.5 to $12.5 \mathrm{mg}$, and of terbutaline from 2.5 to $10 \mathrm{mg}$ 


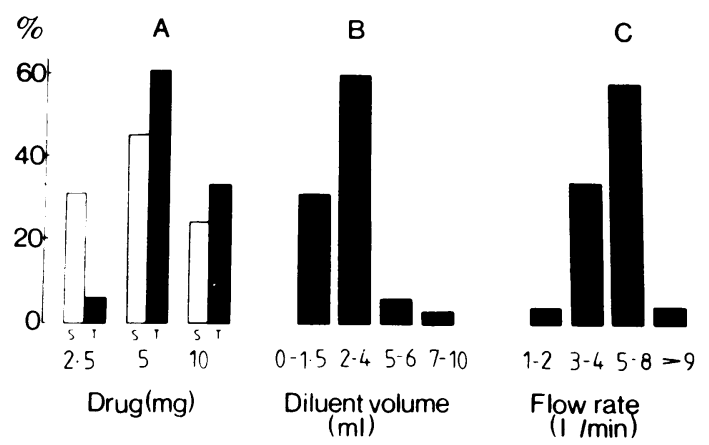

Dose and method of administration of nebulised beta agonist used by the 67 physicians replying to the questionnaire: $A$ dose of nebulised beta agonist prescribed most commonly (S-salbutamol; $T$-terbutaline); $B$ volume of diluent added to drug; $C$ flow rates of gas driving nebuliser.

(fig, A). The dose most frequently prescribed was 5 $\mathrm{mg}$ for both salbutamol (43\% salbutamol users) and terbutaline (61\% terbutaline users).

The beta agonist was diluted in normal saline by $40(60 \%)$ respondents and in water by $24(35 \%)$. Three respondents used no diluent. Diluent volume ranged from $0.5 \mathrm{ml}$ to $10 \mathrm{ml}$, with a mode of $2 \mathrm{ml}$ (fig, B).

The volume of diluent affects the amount of drug left in the residual volume-the volume remaining in the nebuliser after nebulisation to "dryness." Since this will alter the amount of drug given to the patient we calculated the effect of variation in dose and diluent volume for the 16 respondents giving salbutamol via the Inspiron Mini-Neb (residual volume $0.6 \mathrm{ml}$ ) - the most popular combination of nebuliser and beta agonist. The combined effect of the fourfold difference in dose and 20 fold difference in diluent volume used by these physicians resulted in an 11 fold variation in the estimated amount of drug leaving the nebuliser.

Nebuliser units used most frequently by the 67 physicians replying to the questionnaire

\begin{tabular}{ll}
\hline Type of nebuliser used & $\%$ of replies \\
\hline Inspiron Mini-Neb & 41 \\
Bird & 13 \\
Wright & 12 \\
Acorn & 11 \\
Bennet & 11 \\
Others & 12 \\
With IPPV & 19 \\
Without IPPV & 81 \\
\hline
\end{tabular}

IPPV-intermittent positive pressure ventilation.
NEBULISER AND DRIVING FLOW RATE

Several different nebulisers were used by respondents, $28(41 \%)$ physicians using more than one. The Inspiron Mini-Neb was used most frequently, by $28(41 \%)$ physicians (table). Intermittent positive pressure units were use by $13(19 \%)$ physicians.

The nebuliser was fitted with a face mask by 39 $(58 \%)$ respondents, a mouthpiece by $18(27 \%)$, and either by $10(15 \%)$. The nebuliser unit was driven from a wall supply of oxygen in 29 cases (43\%), cylinders of air in $9(13 \%)$, oxygen in $13(20 \%)$, and compressor pump in $16(24 \%)$. The expired air was usually allowed to escape to atmosphere. Four physicians used a one way valve, though it was unclear whether this was for beta agonists or only for nebulised antibiotics. Driving gas flow rates varied from 1 to $10 \mathrm{l} / \mathrm{min}$ (mode $4 \mathrm{l} / \mathrm{min}$ ), $25(38 \%)$ respondents using flow rates of $4 \mathrm{l} / \mathrm{min}$ or less (fig, C). Fifty four $(81 \%)$ continued nebulisation to "dryness"- that is, no further aerosol production by the unit. When the nebuliser was used for a specific time this ranged from 2 to 15 minutes.

\section{ELECTROCARDIOGRAM}

Most physicians (47 or $70 \%$ ) did not monitor the electrocardiogram routinely during nebulisation. Specific reasons for monitoring, such as a previous history of cardiac disease, were mentioned in 10 $(15 \%)$ replies.

\section{Discussion}

All the respondents in this survey used nebulisers to deliver beta agonists, though there was considerable variation in the manner in which they were used. The large number of nebuliser systems used reflects the wide range of units available in Britain-all varying in terms of volume output per minute, the size of aerosol particles they produce, and residual volume. Unfortunately this information is not readily available for most nebulisers.

Although we attempted to obtain a representative cross section of practising physicians with an interest in chest disease by random selection of names from the Thoracic Society handbook, some bias could have been introduced if the non-responders included some physicians not currently practising chest medicine or a preponderance of physicians not using nebulised beta agonists. This does not affect the validity of our principal finding that there is striking variation in the dose and method of administration of nebulised beta agonist treatment

The beta selective agonists salbutamol and terbutaline were the beta agonists preferred by respondents in this study. For both salbutamol and terbutaline the most commonly prescribed dose was 5 
mg, despite the fact that salbutamol is twice as potent as terbutaline..$^{910}$ There was a fivefold difference between the smallest and the largest dose of salbutamol prescribed most commonly by different physicians and a fourfold difference in the case of terbutaline.

The volume of diluent used influences the amount of drug leaving the nebuliser by altering the amount of drug left in the residual volume. For example, if 5 $\mathrm{mg}$ salbutamol $(1 \mathrm{ml})$ is given without diluent via an Inspiron Mini-Neb (residual volume $0.6 \mathrm{ml}$ ), only 2 $\mathrm{mg}$ will leave the nebuliser; if the same amount of salbutamol is diluted in $4 \mathrm{ml}$ saline, twice as much drug will leave the nebuliser. Calculations based on subjects using the Mini-Neb and salbutamol showed an 11 fold variation in the estimated dose of drug leaving the nebuliser.

Many physicians used a gas flow rate of $4 \mathrm{l} / \mathrm{min}$ or less to drive the nebuliser yet high flow rates are necessary to comminute the liquid jet into droplets small enough to enter the airways - that is, a mass median diameter of around $10 \mu \mathrm{m}$ or less. With the Inspiron Mini-Neb, for example, particle size increases from a mass median diameter of $4 \mu \mathrm{m}$ at a flow rate of $8 \mathrm{l} / \mathrm{min}$ to $13 \mu \mathrm{m}$ at $4 \mathrm{l} / \mathrm{min} .{ }^{11}$ The use of low flow rates may be due to concern over a possible reduction of hypoxic drive in hypercapnic patients. This problem is avoided by use of compressed air to drive the nebuliser.

Higher doses of beta agonist are recommended for use in nebulisers than in metered dose inhalers. The dose of salbutamol prescribed most commonly by our respondents $(5 \mathrm{mg})$ is 25 times higher than the usual dose given by the metered dose inhaler $(200 \mu \mathrm{g})$ and for terbutaline it is 10 times higher (5 $\mathrm{mg}$ and $500 \mu \mathrm{g}$ respectively).

It has been suggested that nebulisers are less efficient than metered dose inhalers at delivering drugs to the lung but this will depend on the nebuliser and the way in which it is used. Deposition studies using the Inspiron Mini-Neb have shown that $12 \%$ of the drug leaving the nebuliser can be found in the lung ${ }^{8}$ compared with $8.8 \%$ from a metered dose inhaler. ${ }^{4}$ This is obviously important since airway response to a given dose of beta agonist is similar whether the drug is given by metered dose inhaler or nebuliser. ${ }^{12}$

Few of the respondents monitored cardiac rhythm routinely during nebulisation and this presumably reflects confidence in the safety of nebulised beta agonists. In the study by Choo-Kang and Grant 10 $\mathrm{mg}$ of salbutamol given by intermittent positive pressure ventilation was effective and safe in patients with stable asthma. ${ }^{13}$ The same has been true for subsequent studies of similar or smaller doses of salbutamol and terbutaline given by nebul- iser to patients with both severe ${ }^{14} 15$ and more stable chronic asthma. ${ }^{716}$ These studies were not designed, however, to detect infrequent complications such as arrhythmias and have often excluded patients with heart disease. Adverse cardiovascular effects from beta $_{2}$ agonists are obviously uncommon, although angina has been reported ${ }^{17}$ and we have seen supraventricular tachycardias after nebulised salbutamol. There is a large variation in the heart rate response to beta ${ }_{2}$ agonists ${ }^{16}{ }^{18}$ and some patients will be more susceptible to arrhythmias than others.

There is considerable variation in the way nebulisers are used to administer beta agonists in hospital practice and they are often used inefficiently. Efficiency could be improved by using optimum gas flow rates and diluent volumes. Improved efficiency will increase drug delivery to the lung but it may also increase side effects and the risk of arrythmias. We are not therefore recommending that efficiency should necessarily be improved until more is known about the optimum dose of beta agonists for general use in hospital when the age and medical condition of the patient are taken into account. This survey will allow physicians to see how the dose and method of administration of nebulised beta agonist that they use compare with the practice of other physicians. Studies designed to determine the optimal dose of beta agonists for patients in hospital and at home must specify the type of nebuliser used, flow rate, and diluent volume.

We are most grateful to the physicians who completed the questionnaire.

\section{References}

' Larsson S, Svedymyr N. Bronchodilating effect and side-effects of beta ${ }_{2}$-adrenoceptor stimulants by different modes of administration (tablets, metered aerosol and combinations thereof). Am Rev Respir Dis 1977;116:861-9.

${ }^{2}$ Hetzel MR, Clark TJH. Comparison of intravenous and aerosol salbutamol. Br Med J 1976;ii:919.

${ }^{3}$ Blackwell EW, Briant RH, Conolly ME, Davies DS, Dollery CT. Metabolism of isoprenaline after aerosol and direct intrabronchial administration in man and dog. Br J Pharmacol 1974;50:587-91.

${ }^{4}$ Newman SP, Pavia D, Moren F, Sheahan NF, Clarke SW. Deposition of pressurised aerosols in the human respiratory tract. Thorax $1981 ; 36: 52-5$.

${ }^{5}$ Newman SP, Pavia D, Clarke SW. How should a pressurised $\beta$-adrenergic broncodilator be inhaled? Eur $J$ Respir Dis 1981;62:3-21.

- Asmundsson T, Johnson RF, Kilburn KH, Goodrich JK. Efficiency of nebulizers for depositing saline in human lung. Am Rev Respir Dis 1975;108:506-12.

${ }^{7}$ Ruffin RE, Obminski G, Newhouse MT. Aerosol sal- 
butamol administration by IPPB: lowest effective dose. Thorax 1978;33:689-93.

${ }^{8}$ Lewis RA, Cushley MJ, Fleming JS, Tattersfield AE. Is a nebuliser less efficient than a metered dose inhaler and do pear-shaped extension tubes work? Am Rev Respir Dis 1982;125:94.

9 Sacchetti G, Magni E, Mandelli V, Fiora L. Clinical pharmacology of terbutaline and salbutamol given by inhalation. Clinical Trials Journal 1976;13:81-5.

${ }^{10}$ Bennis J, Svedmyr N. A controlled comparison of salbutamol and terbutaline inhaled by IPPV in asthmatic patients: a dose-response study. Scand J Respir Dis 1977; suppl 101:113-7.

"Lewis RA. Therapeutic aerosols. In: Cumming G, Bonsignore G, eds. Drugs and the lung. London: Plenum Publishing Company (in press).

${ }^{12}$ Cushley MJ, Lewis RA, Cragg DJB, Jackson IL, Tattersfield AE. Administration of a beta-agonist: comparison of three techniques. Thorax 1981;36:714.

${ }^{13}$ Choo-Kang YFJ, Grant IWB. Comparison of two methods of administering bronchodilator aerosol to asthmatic patients. $\mathrm{Br}$ Med J 1975;ii:119-20.

14 Webber BA, Collins JV, Branthwaite MA. Severe acute asthma: a comparison of three methods of inhaling salbutamol. Br J Dis Chest 1982;76:69-74.

is Williams SJ, Winner SJ, Clarke TJH. Comparison of inhaled and intravenous terbutaline in acute severe asthma. Thorax 1981;36:629-31.

${ }^{16}$ Walters EH, Cockroft A, Griffiths T, Rocchiccioli K, Davies BH. Optimal dose of salbutamol respiratory solution: comparison of three doses with plasma levels. Thorax 1981;36:625-8.

${ }^{17}$ Neville E, Corris PA, Vivian J, Nariman S, Gibson GJ. Nebulised salbutamol and angina. $\mathrm{Br} M e d \mathrm{~J}$ 1982;285:796-7.

${ }^{18}$ Lawford P, Jones BJM, Milledge JS. Comparison of intravenous and nebulised salbutamol in initial treatment of severe asthma. Br Med J 1978;i:84.

\section{Appendix: The questionnaire}

1 How often do you prescibe nebulised beta-agonists per month? (0,1-5, 5-10, More than 10)

2 Drug most commonly prescribed Other)

3 Dose most commonly prescribed (...mg)

4 Diluting solution (Saline, Distilled water, Other)

5 Volume of diluent $(\ldots \mathrm{ml})$

6 Type of nebuliser used (Pulmasonic, Inspiron Mini-Neb, Wrights, Acorn, Sandoz lifeline, Bird, Bennet, Other)

7 Facemask or mouthpiece

8 Is your nebuliser used with IPPV?

9 Do you let aerosol go to atmosphere during expiration (as opposed to having a one way valve)?

10 Mechanisms for providing compressed air/oxygen cylinder, Oxygen cylinder, Wall oxygen, Compressor pump)

11 Gas flow rate $(. .1 / \mathrm{min})$

12 End point of delivery

(To dryness, Specified time ( $\mathrm{min})$ )

13 Proportion of patients with ECG monitoring during nebulisation $(0 \%$, Less than $33 \%$, Less than $66 \%$, More than $66 \%$, $100 \%$ )

14 When do you monitor? acutely ill, Other)

(All the time, Only when patient is 